\title{
Retinoblastoma Extending up to the Optic Chiasma and Presenting as a Suprasellar Mass
}

\author{
Himanshu Mishra $M B B S^{1}$ iD, Amit Kumar $M D^{2}$ \\ 1,2 Department of Radio-diagnosis, IGIMS, Patna, India
}

Date of submission: $24^{\text {th }}$ May 2021

Date of acceptance: $31^{\text {st }}$ October 2021

Date of publication: $1^{\text {st }}$ December 2021

\begin{abstract}
Retinoblastoma is the most common ocular malignancy of childhood. It is present in childhood with leukocoria and strabismus. Most patients are diagnosed under 3 years of age.

Funduscopic examination can reveal an intraocular mass, but imaging is essential for complete evaluation of the lesion. Although ultrasound is a non-invasive and relatively inexpensive screening tool, cross-sectional imaging is required to assess the involvement of optic nerve and intracranial spread.

We report a case of retinoblastoma in a 5 year old male child who presented with headache diminution of vision in both eyes. Contrast enhanced magnetic resonance imaging (MRI) revealed an enhancing soft tissue mass in the right eye with involvement of optic nerve and optic chiasma and contiguous with a large suprasellar mass causing hydrocephalus. Non-contrast computed tomography (CT) showed extensive calcifications in the mass lesion.
\end{abstract}

Key words: CT, Imaging, MRI features, Retinoblastoma, Staging.

\section{Introduction}

$\mathrm{R}$ etinoblastoma is a malignancy of the paediatric age group which arises from the primitive photoreceptors or neuronal retinal cells in the eye. Its global incidence is about 1 in 16,000-18,000 live births, although it may be slightly higher in middle and low income countries. ${ }^{1}$

When the disease is unilateral (in around $60 \%$ of cases), the median age at diagnosis is 2 years. When the disease is bilateral (in around $40 \%$ of cases), the median age at diagnosis is 1 year. $^{2}$ Most patients present with leukocoria and strabismus, although other symptoms may be observed, including rubeosis iridis, buphthalmos, hypopyon, hyphema. ${ }^{2}$

Access this article online
Website: https://www.nepjol.info/index.php/NJN
DOI: https://doi.org/10.3126/njn.v18i4.37248
HOW TO CITE
Mishra H, Kumar A. Retinoblastoma Extending up to the
Optic Chiasma and Presenting as a Suprasellar Mass. NJNS.
2021;18(4):64-7.

Address for correspondence:

Dr. Amit Kumar

Associate Professor,

Department of Radio-diagnosis,

IGIMS, Patna, Bihar, India.

E-mail: amitmd2008@gmail.com

Phone: +91 8210527229

Copyright (C) 2021 Nepalese Society of Neurosurgeons (NESON)

ISSN: 1813-1948 (Print), 1813-1956 (Online)

This work is licensed under a Creative Commons Attribution-Non Commercial 4.0 International License.
Classic imaging findings in retinoblastoma include a retrolental mass which often contains foci of calcification. Ultrasound is often used as a preliminary investigation while cross-sectional imaging such as computed tomography (CT) and magnetic resonance imaging (MRI) can confirm the diagnosis by demonstrating an endophytic or exophytic mass which enhances avidly on post-contrast studies. ${ }^{3}$

Retinoblastomas may spread hematogenously, via the lymphatics, or along the optic nerve sheath. Vitreal seeding and drop metastases within the subarachnoid space are common. ${ }^{4} 5$ Chiasmal involvement which presents as a suprasellar mass lesion is relatively uncommon, which we describe in our case report.

\section{Case report}

A 5-year-old male child presented to the out-patient department with complaints of headache and severe diminution of vision in both eyes. Dilated fundoscopy revealed a cream coloured endophytic mass with adjacent dilated blood vessels in the right eye. Funduscopic examination of the left eye revealed no significant abnormalities.

Contrast enhanced MRI showed an avidly enhancing soft tissue lesion in the posterior segment of the right eye, extending posteriorly along the optic nerve, involving the optic chiasma, and forming a suprasellar mass effacing the third ventricle and causing moderate dilatation of both the lateral ventricles. Optic canal was widened and mild proptosis was present. (Figures 1, 2 and 3)

Screening non-contrast CT scans of the brain and orbits revealed extensive calcification in the intraocular lesion, the optic nerve, and the suprasellar mass. (Figures $4 \mathrm{~A}, \mathrm{~B}$ and $\mathrm{C}$ ) 

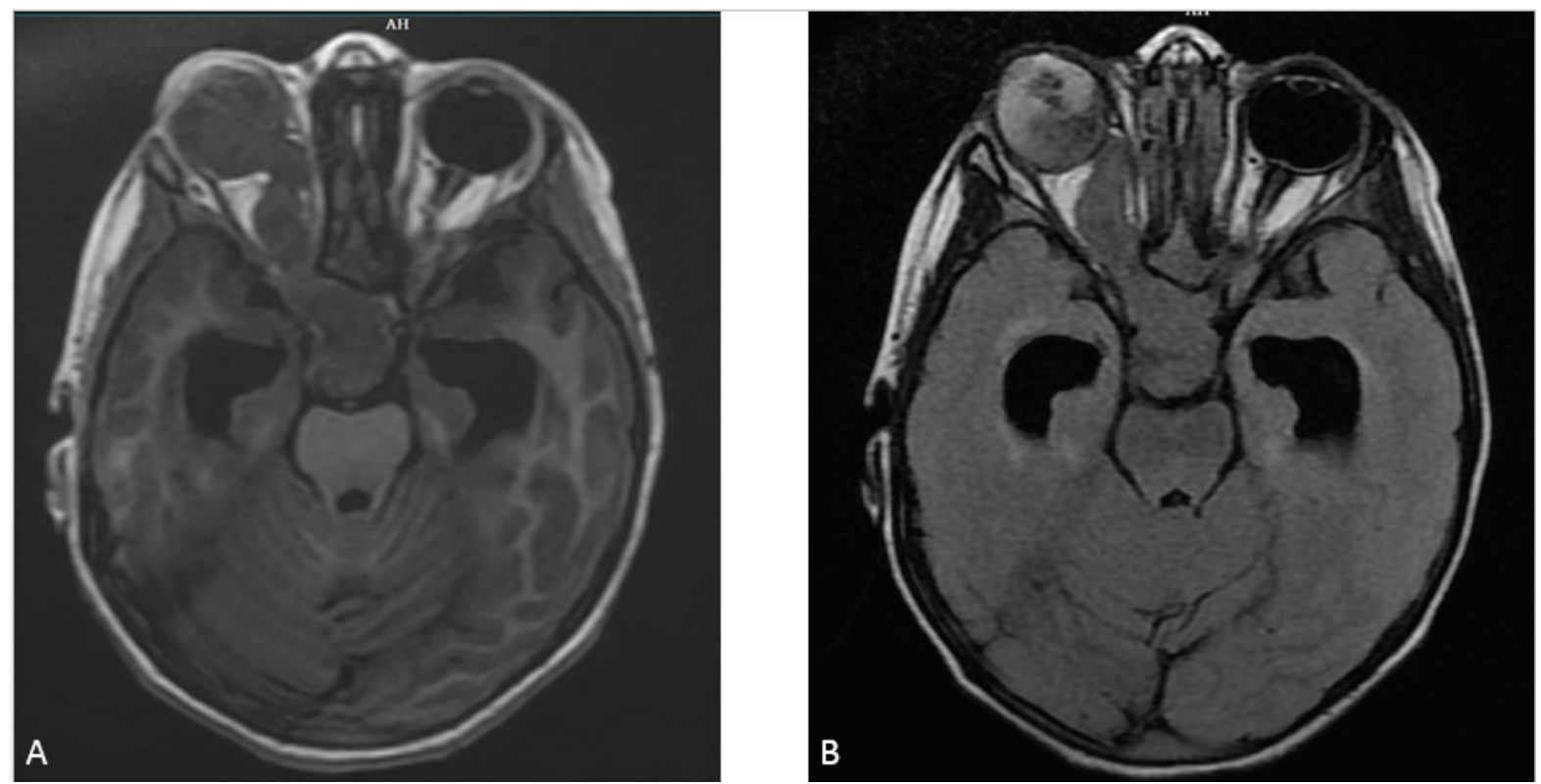

Figure 1: (A) Axial T1 and (B)T2-FLAIR images at the level of the orbits show an isointense soft tissue mass in the right globe suggestive of retinoblastoma. It involves the right optic nerve as well as extending intracranially through the optic canal to involve the optic chiasma.
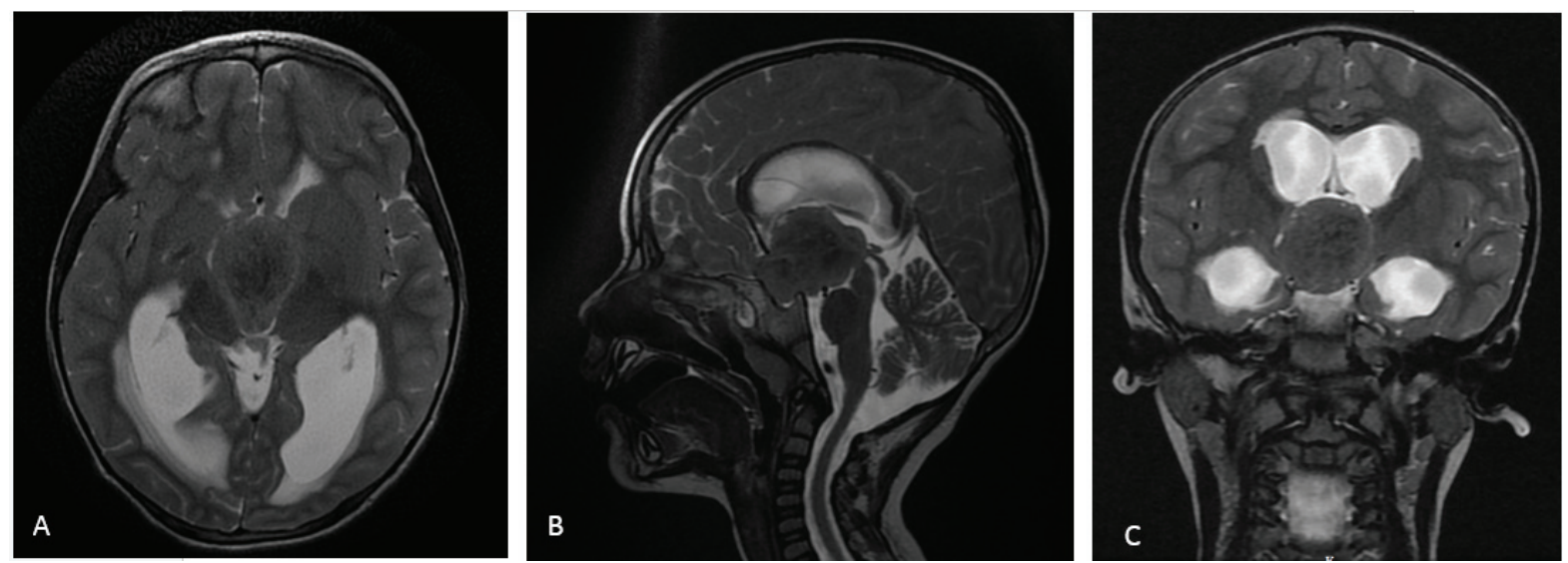

Figure 2: (A) Axial, (B) sagittal, and (C) coronal T2 images showing the true intracranial extent of the retinoblastoma. This suprasellar mass is seen compressing the third ventricle leading to dilatation of the lateral ventricles.
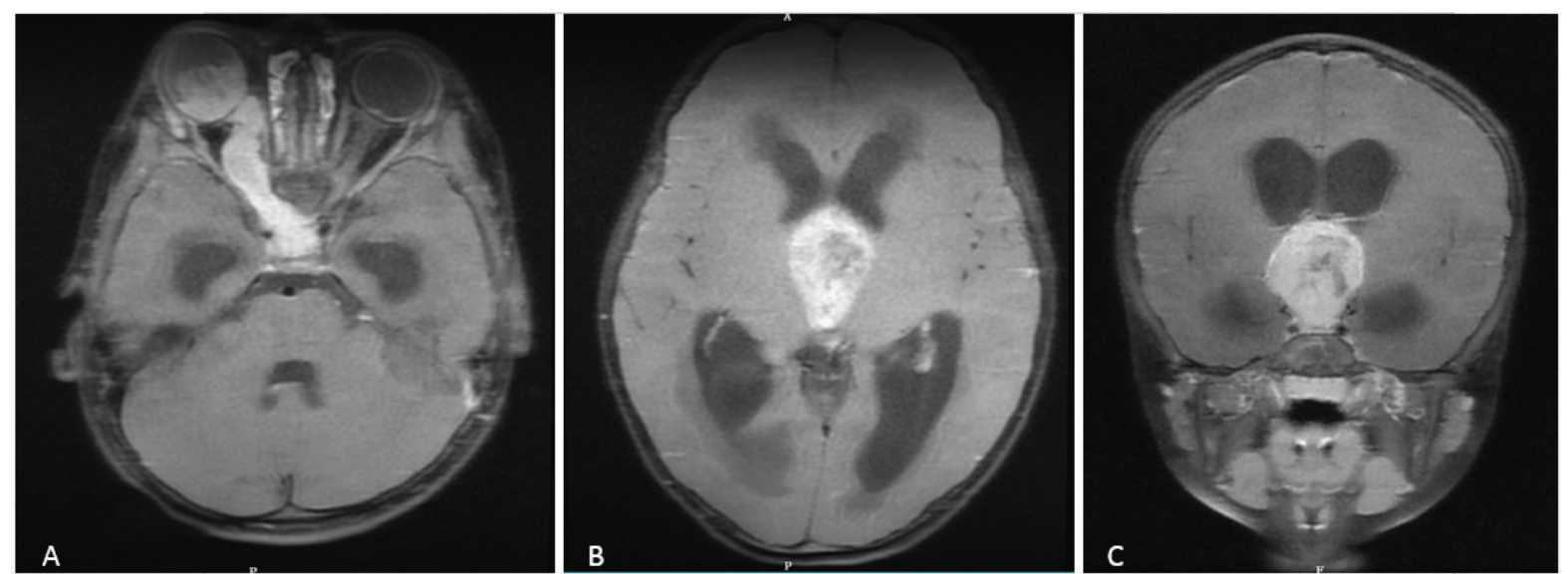

Figure $3(A, B, C)$ : Post contrast MR images show that the soft tissue component of the retinoblastoma is avidly enhancing. 

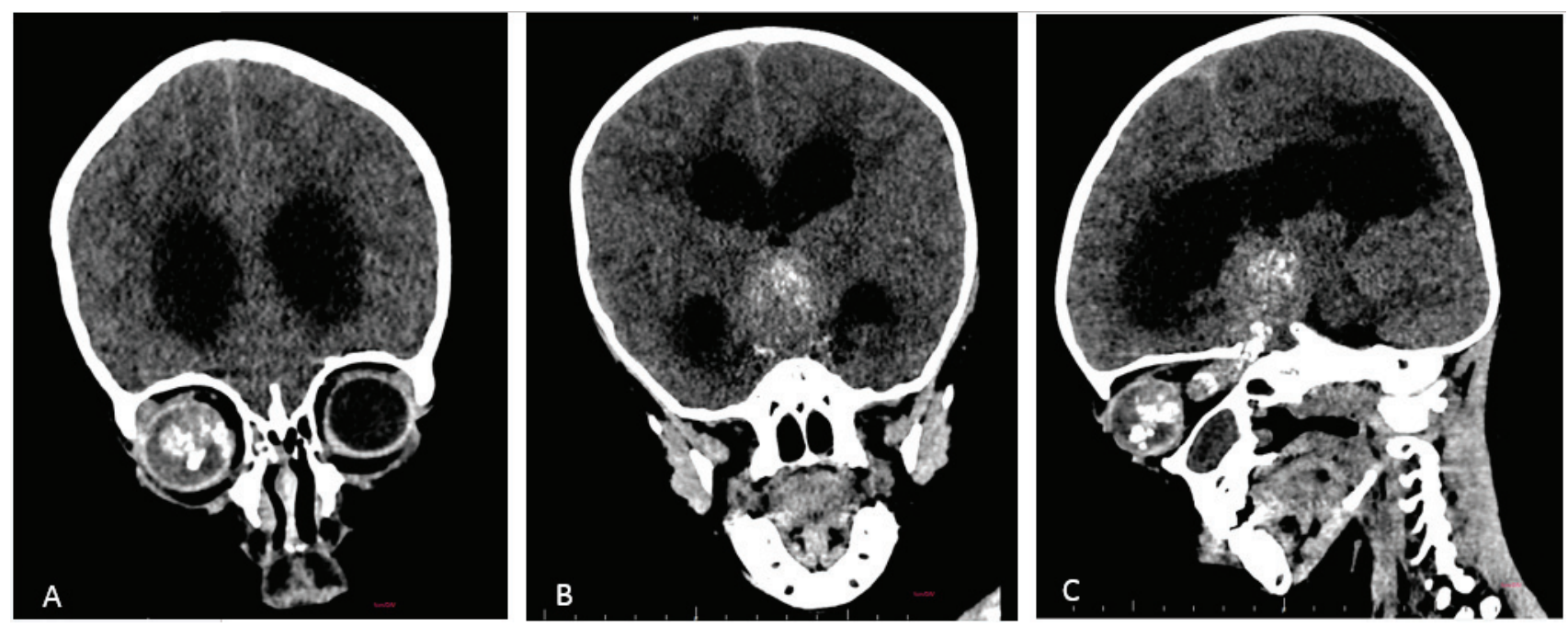

Figure $4(A, B, C)$ : Non-contrast CT images showing extensive calcification of the retinoblastoma which has involved the optic nerve and optic chiasma, and presented as a suprasellar mass.

\section{Discussion}

Retinoblastoma is the most common primary intraocular malignant tumour in the paediatric age group. Around $40 \%$ of retinoblastomas are heritable, frequently bilateral, and present early (median age at diagnosis is 1 year). These are associated with a germline mutation of the $R B 1$ gene. ${ }^{2,4}$ Remaining $60 \%$ are sporadic, usually unilateral, and present relatively late (median age at diagnosis is 2 years). These tumours have somatic $R B 1$ gene mutations. $R B 1$ is a tumour suppressor gene located on the chromosome 13q14., ${ }^{2,4}, 5$

Most common presenting symptoms are leukocoria, strabismus, and proptosis. When the tumour is exophytic, it may lead to non-rhegmatogenous retinal detachment and consequently sudden painless loss of vision in the affected eye. Intracranial extension is relatively rare but when present can result in hydrocephalus leading to headaches and increased susceptibility to seizures. ${ }^{2,6}$ Our patient presented with headache (due to hydrocephalus) and loss of vision in both eyes (due to involvement of optic chiasma).

Imaging is imperative for pre-treatment evaluation. Ultrasound confirms the diagnosis by demonstrating an irregular intraocular mass which is usually more echogenic than the vitreous body and contains foci of calcifications, which are easily recognised by the posterior acoustic shadows. Cross-sectional imaging such as CT and MRI helps to delineate the true extent of the tumour as well as identify if there is a coexistent retinoblastoma in the apparently normal eye (since small retinoblastomas can be missed by clinical examination alone) and whether a pineoblastoma is present in addition to the retinoblastoma (so-called trilateral retinoblastoma). ${ }^{3}$

MRI, especially contrast enhanced MRI, is superior to other imaging modalities to evaluate the extent of optic nerve involvement, extraocular \& intracranial extension, and leptomeningeal spread. Vitreal and subretinal seeding may also be detected by high resolution fast spin echo sequences although their absence at MRI does not exclude their presence. ${ }^{7,8,9}$ In our case, the tumour had spread via the optic nerve to involve the optic chiasma. There were no obvious vitreal or subretinal seeds.

Chemoradiotherapy was offered as the primary treatment modality but the parents declined and the patient was subsequently lost to follow up.

\section{Conclusion}

Imaging, especially contrast enhanced MRI, is invaluable for pre-operative staging of the disease and evaluating the prognosis \& potential for vision in the affected eye. So the current recommendation for any newly diagnosed case of retinoblastoma is to undergo an MRI for early detection and proper evaluation. Treatment of retinoblastoma is multidisciplinary and multimodal, and includes surgery, radiotherapy, cryotherapy, and chemotherapy, depending on the clinical context. A tumour confined within the eyeball has a survival rate of $90 \%$ at 5 years while mortality reaches over $90 \%$ if tumour extended outside the eyeball.9, 10

\section{Conflict of Interest: None}

Source(s) of support: None

\section{References}

1. Dimaras H, Corson TW, Cobrinik D, White A, Zhao J, Munier FL, Abramson DH, Shields CL, Chantada GL, Njuguna F, Gallie BL. Retinoblastoma. Nat Rev Dis Primers. 2015;27(1):15021. https://doi. org/10.1038/nrdp.2015.21 
2. Aerts I, Lumbroso-Le Rouic L, Gauthier-Villars M, Brisse H, Doz F, Desjardins L. Retinoblastoma. Orphanet J Rare Dis. 2006 Aug 25;1:31. https:/doi. org/10.1186/1750-1172-1-31

3. de Graaf P, Göricke S, Rodjan F, Galluzzi P, Maeder P, Castelijns JA, Brisse HJ; European Retinoblastoma Imaging Collaboration (ERIC). Guidelines for imaging retinoblastoma: imaging principles and MRI standardization. Pediatr Radiol. 2012;42(1):2-14. https://doi.org/10.1007/s00247-011-2201-5

4. Singh L, Kashyap S. Update on pathology of retinoblastoma. Int J Ophthalmol. 2018 Dec 18;11(12):2011-2016. https://doi.org/10.18240/ ijo.2018.12.22

5. Ray A, Gombos DS, Vats TS. Retinoblastoma: an overview. Indian J Pediatr. 2012 Jul; 79(7): 91621. https://doi.org/10.1007/s12098-012-0726-8. Erratum in: Indian J Pediatr. 2012;79(8):1109. Vats, Tribhawan S [added]. PMID: 22421935.

6. Padma M, Kumar N, Nesargi PS, Aruna Kumari BS, Appaji L, Viswanathan A. Epidemiology and clinical features of retinoblastoma: A tertiary care center's experience in India. South Asian J Cancer. 2020;9(1):56-58. https://doi.org/10.4103/sajc. sajc_89_19
7. Rauschecker AM, Patel CV, Yeom KW, Eisenhut CA, Gawande RS, O’Brien JM, Ebrahimi KB, DaldrupLink HE. High-resolution MR imaging of the orbit in patients with retinoblastoma. Radiographics. 2012; 32(5):1307-26. https://doi.org/10.1148/rg.325115176

8. Shields CL, Mashayekhi A, Au AK, Czyz C, Leahey A, Meadows AT, Shields JA. The International Classification of Retinoblastoma predicts chemoreduction success. Ophthalmology. 2006;113(12): 2276-80. https://doi.org/10.1016/j. ophtha.2006.06.018

9. Chantada G, Doz F, Antoneli CB, Grundy R, Clare Stannard FF, Dunkel IJ, Grabowski E, Leal-Leal C, Rodríguez-Galindo C, Schvartzman E, Popovic MB, Kremens B, Meadows AT, Zucker JM. A proposal for an international retinoblastoma staging system. Pediatr Blood Cancer. 2006;47(6):801-5. https://doi. org/10.1002/pbc.20606

10. Khurana A, Eisenhut CA, Wan W, Ebrahimi KB, Patel C, O’Brien JM, et al. Comparison of the diagnostic value of MR imaging and ophthalmoscopy for the staging of retinoblastoma.European Radiology 2013;23(5):1271-1280. https://doi.org/10.1007/ s00330-012-2707-8 